\title{
Conservative management of transverse partial flexor digitorum profundus tendon lacerations in zone 2
}

\author{
MM Al-Qattan MB BS FRCSC, \\ Division of Plastic Surgery, King Saud University, Riyadh, Saudi Arabia \\ HM Clarke MD, V Bowen MD \\ Division of Plastic Surgery, University of Toronto, Toronto, Ontario
}

\begin{abstract}
MM Al-Qattan, HM Clarke, V Bowen. Conservative management of transverse partial flexor digitorum profundus tendon lacerations in zone 2. Can J Plast Surg 1995;3(3):157-160. The experience with six patients managed conservatively following transverse partial flexor digitorum profundus tendon lacerations in zone 2 is presented. Four patients who were mobilized using elastic traction experienced no triggering; however, two patients who had unrestricted mobilization immediately following injury developed triggering. The mechanism of triggering and tendon flap formation in the clinical cases is discussed.
\end{abstract}

Key Words: Hand injury, Flexor tendons, Tendon injury

Traitement conservateur des lacérations du tendon du fléchisseur digital transverse profond en zone 2

RÉSUMÉ: Cet article présente le cas de six patients traités de façon conservatrice après lacération du tendon du fléchisseur digital profond en zone 2. Quatre patients qui ont été mobilisés par traction élastique n'ont manifesté aucun effet de gâchette. Toutefois, deux patients qui n'avaient aucune restriction sur le plan de la mobilité ont tout de suite manifesté un effet de gâchette associé à la blessure. Le mécanisme de l'effet de gâchette et la formation d'un lambeau tendineux sont présentés ici sous la forme de cas cliniques.

The literature provides two theories to explain the mechanism of triggering following conservative management of transverse partial lacerations of flexor tendons. The first theory was proposed by Kleinert (1) and states that allowing a partially severed tendon to go unsutured invites the development of a bulbous scar at the site of laceration which in turn results in triggering (Figure 1). 


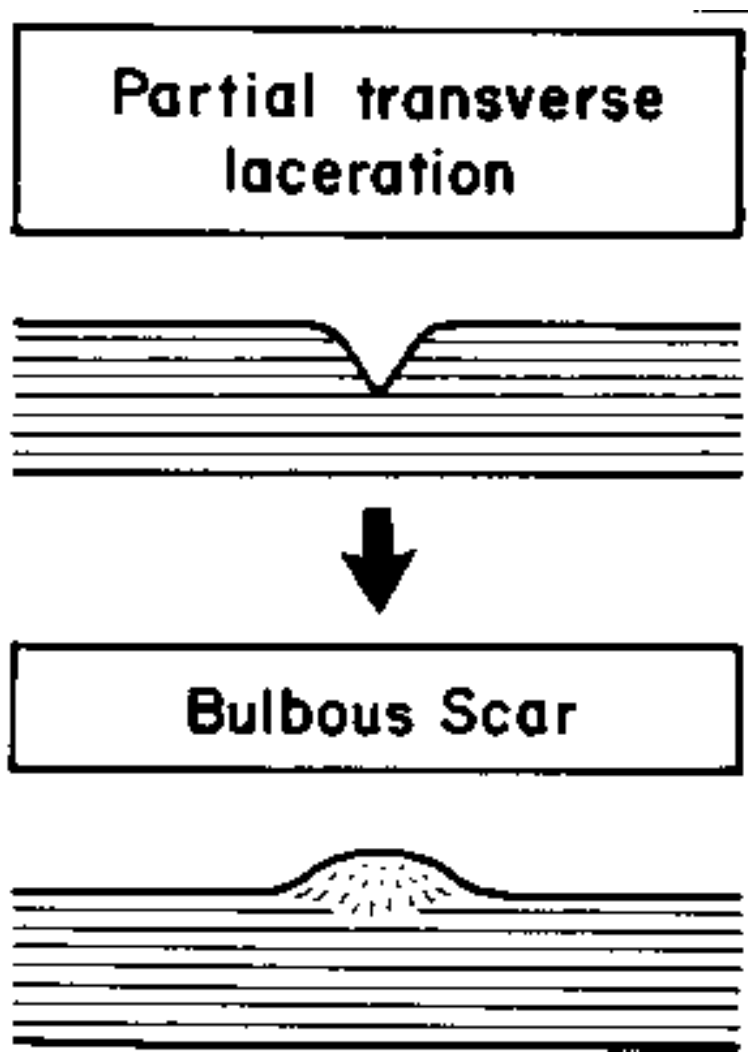

Figure 1) Mechanism of triggering following conservative management of transverse partial lacerations of flexor tendons as proposed by Kleinert (1)

The second theory, proposed by Al-Qattan et al (2), was based on an experimental study in sheep. Triggering following unrepaired transverse lacerations of the flexor digitorum profundus (FDP) tendons in that experimental model was not caused by bulbous scar formation but by bunching of the tendon fibres proximal or distal to the laceration site. If this bunched part of the tendon became incorporated into the healing process, gradual spontaneous resolution of triggering occurred. Failure of incorporation of this bunched part resulted in tendon flap formation and triggering (Figure 2).

In this paper, we present our experience with six patients managed conservatively following transverse partial FDP tendon lacerations in zone 2. 


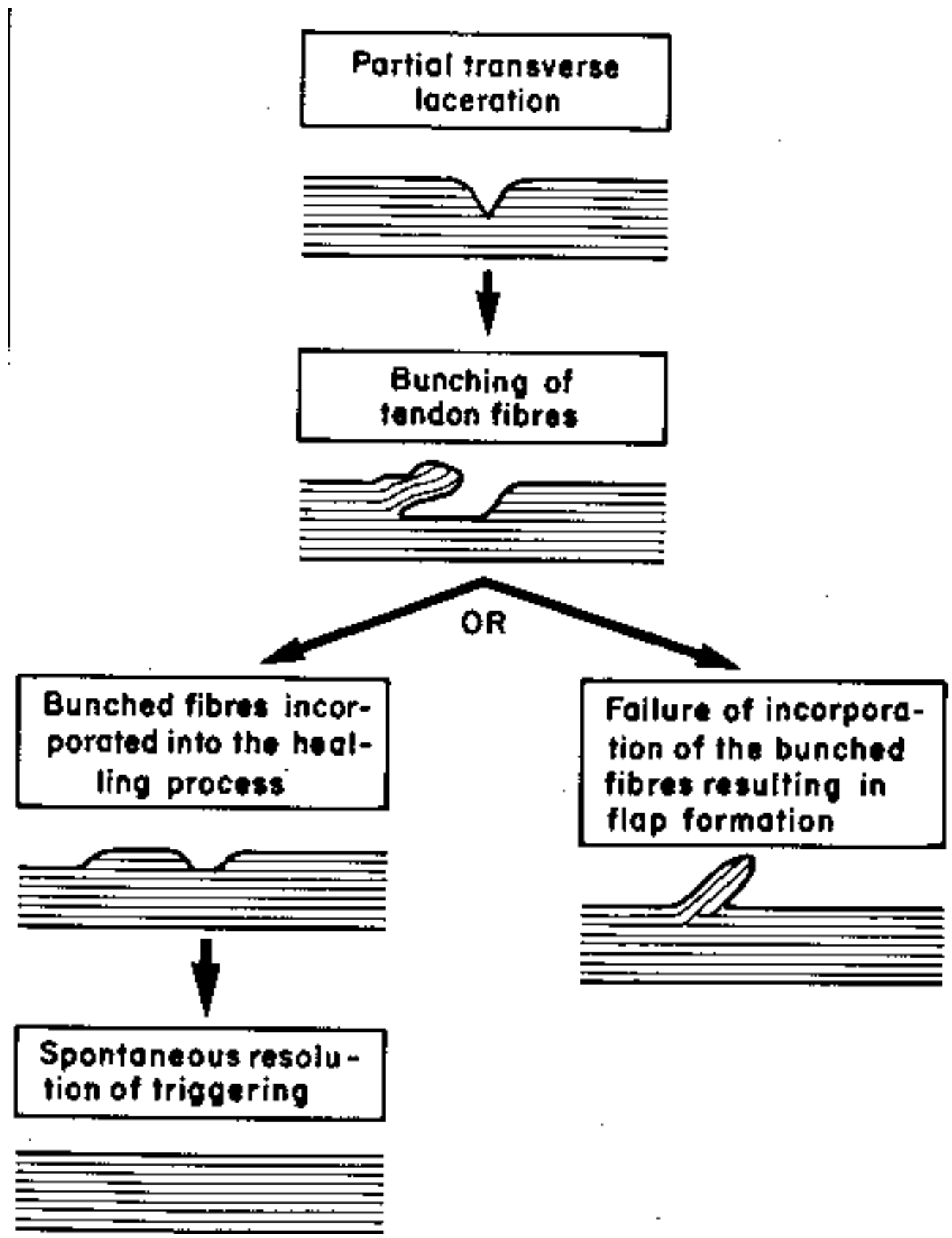

Figure 2) Mechanism of triggering following conservative management of transverse partial lacerations of flexor tendons as proposed by Al-Qattan et al (2)

\section{PATIENTS}

The study was restricted to tidy wounds involving partial transverse division of the FDP tendon in zone 2, confirmed on exploration. Summary of patients' data is shown in Table 1. There were four males and two females and the age ranged between 12 and 40 years. The percentage division of the FDP tendon varied between 20 and $50 \%$ of the cross sectional area, and in all cases, the tendon laceration was not sutured but the skin wound was closed. 
TABLE 1: Six patients managed conservatively following transverse partial flexor digitorum profundus (FDP) tendon lacerations in zone 2

\begin{tabular}{|l|l|l|l|l|l||}
\hline Number & Age/sex & $\begin{array}{l}\text { Finger } \\
\text { involved }\end{array}$ & $\begin{array}{l}\text { \% division of } \\
\text { FDP }\end{array}$ & $\begin{array}{l}\text { Mobilization after } \\
\text { injury }\end{array}$ & Triggering \\
\hline 1 & $30 / \mathrm{F}$ & Middle & 20 & Elastic traction & No \\
\hline 2 & $25 / \mathrm{M}$ & Index & 40 & Elastic traction & No \\
\hline 3 & $40 / \mathrm{F}$ & Index & 30 & Elastic traction & No \\
\hline 4 & $39 / \mathrm{M}$ & Ring & 50 & Elastic traction & No \\
\hline 5 & $15 / \mathrm{M}$ & Ring & 20 & Unrestricted & Yes \\
\hline 6 & $12 / \mathrm{M}$ & Middle & 30 & Unrestricted & Yes \\
\hline
\end{tabular}

F Female;M Male

The first four patients (cases 1 to 4) were initially seen by us and were mobilized immediately after injury using elastic traction for three weeks, after which active unrestricted mobilization was started. One patient (case 5) was also initially seen by us but refused to use the elastic traction for mobilization. The last patient (case 6) was initially seen at another institution and had no special instructions or splint. The latter two patients used their injured hands actively against resistance from the time of injury.

\section{RESULTS}

All patients who were mobilized using elastic traction experienced no triggering and had full range of motion at the final follow-up examination. On the other hand, the two patients who had unrestricted mobilization developed triggering three to five days after injury. In one case (case 5), triggering resolved spontaneously over a two month period and full range of motion of the digit was eventually obtained. Triggering with limited flexion persisted in the other case (case 6) and surgical exploration was performed four months after injury. Exploration revealed a rent in the flexor sheath just distal to the A2 pulley. On flexion, a distally based flap of FDP passed through and became caught in the rent of the sheath, thereby limiting the excursion of the tendon. The sheath was opened and the tendon flap excised (Figure 3). After closure of the flexor sheath and skin, a splint was applied with elastic band traction for mobilization. The splint was removed three weeks after surgery, and the patient was allowed unrestricted active motion, and eventually regained a full range of motion. 

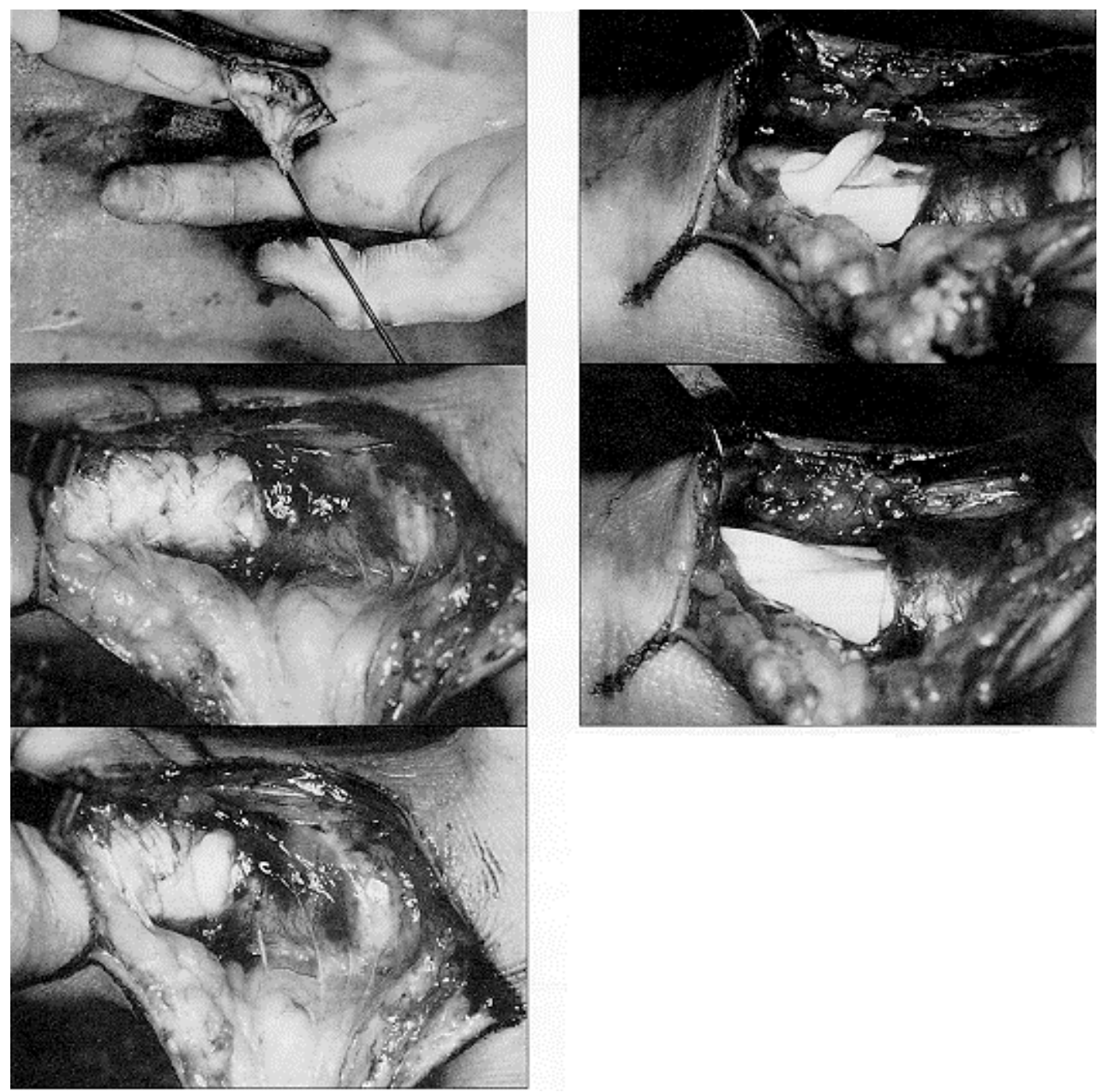

Figure 3) (Top left) Exposure of the flexor sheath of the middle finger in a 12-year-old boy with triggering following partial laceration of the flexor digitorum profundus (FDP) tendon. The following intraoperative photographs are presented in the same orientation. (Middle left) Note the rent in the flexor sheath just distal to the A2 pulley. (Bottom left) On flexion of the digit, a distally based flap of FDP passed through and became caught in the rent of the sheath. (Top right) The sheath was opened revealing the tendon flap. (Middle right) Appearance after excision of the tendon flap

\section{DISCUSSION}

In partial flexor tendon lacerations, it is important to differentiate between bevelled and transverse lacerations. There is a general agreement that bevelled partial tendon lacerations carry a high risk of triggering and therefore should be treated surgically either with excision of the bevelled portion of the tendon or with suturing (17).

The management of transverse partial lacerations of flexor tendons remains controversial. Experimentally, several authors (8-10) concluded that the results in unrepaired partially divided tendons were superior to other forms of treatment. However, 
Chow and $\mathrm{Yu}(11)$ obtained better results after suture and immobilization of partially cut flexor tendons in chickens.

Clinically, Kleinert (1) recommended suture of incompletely severed tendons while others $(5,7,12)$ obtained excellent results without suture followed by early mobilization. The method of mobilization in clinical cases varied. Wray et al (12) instructed their patients to use active motion of sufficient force to produce only mild discomfort, and movement against resistance was not allowed for three weeks. McGeorge and Stilwell (5) mobilized all partially divided tendons using elastic traction for three weeks, after which active unrestricted mobilization was started. We have had similar excellent results in all patients mobilized with elastic traction.

Although several clinical cases of triggering after partial flexor tendon injuries have been reported $(3,6,13,14)$, only one experimental study has investigated the mechanism of triggering (2). The bunching theory proposed by that study (Figure 2) may explain the trigger phenomenon in the two patients described in the current clinical series. Unrestricted mobilization against resistance is associated with excessive tension in the tendon. This, in turn, leads to bunching of the tendon fibres causing triggering. Triggering occurs soon after the unrestricted mobilization (three to five days in our patients) and before collagen or scar formation at the site of tendon laceration. Spontaneous resolution of triggering that occurred in our fifth patient was probably due to the incorporation of the bunched fibres into the healing process. Failure of incorporation of the bunched part of the tendon into the healing process resulted in flap formation in our last patient. At the time of surgical exploration we noted the similarity between the appearance of the flap in the clinical case (Figure 3, top right) and the experimental FDP tendon (Figure 4).

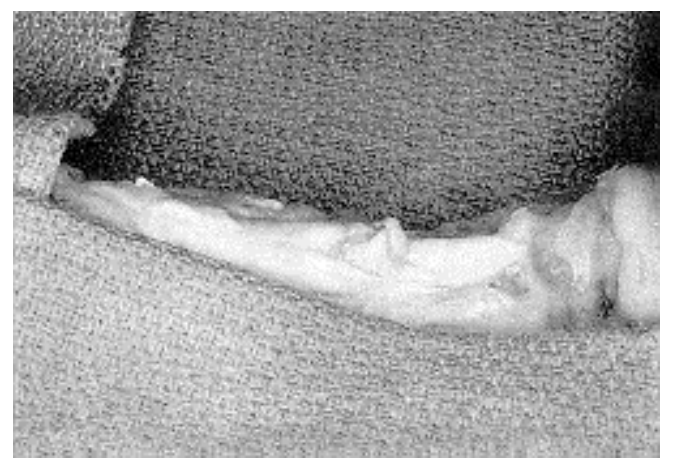

Figure 4) Tendon flap of the left FDP tendon in the sheep following partial tendon laceration and unrestricted mobilization (From Al-Qattan et al [2]). Note the similar appearance of the tendon flap in the clinical case (Figure 3, top right)

We recommend treating transverse partial flexor tendon lacerations conservatively with elastic traction mobilization.

\section{REFERENCES}

1. Kleinert HE. Should an incompletely severed tendon be sutured? (Comment) Plast Reconstr Surg 1976;57:236.

2. Al-Qattan MM, Posnick JC, Lin KY. Triggering after partial tendon laceration. J Hand Surg 1993;18B:241-6. 
3. Janecki C J. Triggering of the finger caused by flexor tendon laceration: Report of two cases. J Bone Joint Surg 1976;58A:1174-5.

4. Kleinert HE, Kalisman M, Steyers CM. Complications in flexor tendon injuries. In:

Boswick JA (ed). Complications in Hand Surgery. Philadelphia: WB Saunders, 1986:1928.

5. McGeorge DD, Stilwell JH. Partial flexor tendon injuries: To repair or not. J Hand Surg 1992;17B:176-7.

6. Schlenker JD, Lister GD, Kleinert HE. Three complications of untreated partial laceration of flexor tendon: Entrapment, rupture and triggering. J Hand Surg 1981;64:392-6.

7. Wray RC, Weeks PM. Treatment of partial tendon lacerations. Hand 1980;12:163-6.

8. Bishop AT, Cooney WP, Wood MB. Treatment of partial flexor tendon lacerations:

The effects of tenorrhaphy and early protected mobilization. J Trauma 1986;26:301-12.

9. Ollinger H, Wray RC, Weeks PM. Effects of suture on tensile strength gain of partially and completely severed tendons. Surg Forum 1975;26:63-4.

10. Reynolds B, Wray RC, Weeks PM. Should an incompletely severed tendon be sutured ? Plast Reconstr Surg 1976;57:36-8.

11. Chow SP, Yu OD. An experimental study on incompletely cut chicken tendons: A comparison of two methods of management. J Hand Surg 1984;9B:121-5.

12. Wary RC, Holtmann B, Weeks PM. Clinical treatment of partial tendon lacerations without suturing and with early motion. Plast Reconstr Surg 1977;59:231-4.

13. Minami A, Ogino T. Trigger wrist caused by a partial laceration of the flexor superficialis tendon of the ring finger. J Hand Surg 1986;11B:457-9.

14. Takami H, Takahashi SM, Ando M. Triggering of the finger secondary to partial flexor tendon tear after closed direct injury. J Hand Surg 1993;18A:881-2. 